\title{
Anisochromia Measurement
}

National Cancer Institute

\section{Source}

National Cancer Institute. Anisochromia Measurement. NCI Thesaurus. Code C161354.

A measurement of the color variation of erythrocytes in a biological specimen. 